\title{
Comparative data on the protection performance of celery, pomegranate and green tea distillates on mild steel in weak $\mathrm{H}_{2} \mathrm{SO}_{4}$ solution
}

\author{
Roland Tolulope Loto ${ }^{\mathrm{a}, *}$, Cleophas Akintoye Loto ${ }^{\mathrm{a}}$, Fope Oyedeko ${ }^{\mathrm{a}}$ \\ ${ }^{a}$ Department of Mechanical Engineering, Covenant University, Ogun State, Nigeria
}

\section{A R T I C L E I N F O}

\section{Article history:}

Received 1 July 2021

Received in revised form 10 August 2021

Accepted 12 August 2021

Available online 26 August 2021

\section{Keywords:}

Carbon steel

Corrosion

Essential oil

Inhibitor

\begin{abstract}
A B S T R A C T
The non-toxic properties of plant distillate for application as corrosion inhibitors is an effective alternative to the toxic conventional derivatives currently applied in industries. Data on the corrosion inhibition effect of celery, pomegranate and green tea distillates on mild steel corrosion in $0.5 \mathrm{M} \mathrm{H}_{2} \mathrm{SO}_{4}$ from coupon analysis is presented. Results showed the distillates performed poorly at low concentrations from $15 \%$ to $45 \%$ distillate concentration. At 60\% distillate concentration, their inhibition performance was average, but below the values for effective inhibition performance with final inhibition efficiency values of $54.55 \%, 48.65 \%$ and $32.39 \%$ for celery, pomegranate and green tea distillates. However, at $75 \%$ concentration, the inhibition efficiency values significantly increased to $85.74 \%, 82.85 \%$ and $62.70 \%$. At $90 \%$ distillate concentration, the inhibition efficiency outputs of the distillates increased further to $95.83 \%, 87.08 \%$ and $92.37 \%$ signifying effective inhibition performance of the distillates. Statistical analysis through ANOVA shows distillate concentration strongly influence the corrosion inhibition performance of the distillates with values above $90 \%$ compared to exposure time with values below $7 \%$, which is relatively negligible but statistically relevant. Generally, the results show the distillates are effective at high concentration with respect to distillate concentration.

(C) 2021 Elsevier Ltd. All rights reserved.

Selection and Peer-review under responsibility of the scientific committee of the Global Conference on Recent Advances in Sustainable Materials 2021.
\end{abstract}

\section{Introduction}

Corrosion is the gradual or accelerated depreciation of the mechanical, physical and aesthetic attributes of metallic alloys resulting from the molecular interaction of the alloy with their environment [1-4]. According to NACE, the total cost of corrosion damage worldwide amounts to $\$ 2.5$ trillion [5]. Industrial operations such as petrochemical refining, chemical processing, fertilizer production, acid descaling, oil and gas pipelines, heat exchangers, automobile radiators, desalination and energy generation extensively use carbon steels for construction of structures, equipment and components due to low cost of production and retail value, reusability and ease of fabrication [6-8]. Carbon steel is the largest steel produced worldwide constituting about $80 \%$ of the total tonnage produced. The steel exhibits low resistance to corrosion by contrast to stainless steels because of the absence of inert protective oxide which forms on stainless steel surface. Corrosion of carbon steels is a prevailing problem resulting in extensive damage to

\footnotetext{
* Corresponding author.

E-mail address: tolulope.loto@covenantuniversity.edu.ng (R. Tolulope Loto).
}

metallic parts, plant shut downs, toxic leakages, and industrial accidents etc. These are responsible for the expensive maintenance and rectifications, and huge financial loss [9]. Sulphate anions exist in aqueous electrolyte in petrochemical distillation unit, oil well maintenance, rust removal, desalination and pickling processes, chemical production etc. where they cause significant damage to the steels in service [10]. Their effect can be mitigated through the utilization of fluid derivatives tagged as corrosion inhibitors. Corrosion inhibitors are one of the most economical techniques of stifling corrosion attack [11-15]. Research has identified corrosion inhibitors with heteroatoms such as $\mathrm{O}, \mathrm{N}$, and $\mathrm{S}$ to be highly effective and strongly adsorb unto the ferrous alloys. This phenomenon is also a product of the physical and chemical characteristics of the inhibitor, reactive groups, electron configuration of the contributor atom, p-orbital property, and the electronic configuration of inhibitor molecules [16-22]. However, conventional corrosion inhibiting compounds are toxic, carcinogenic and severely contaminate the environment. Application of sustainable and biodegradable compounds has been proven to be effective in suppressing the oxidation and reduction of half-cell reactions [23-31]. The data in this article compares the protection efficiency of celery, 
pomegranate and green tea distillates on mild steel in $0.5 \mathrm{M} \mathrm{H}_{2} \mathrm{SO}_{4}$ solution (See Fig. 1).

\section{Experimental methods}

Mild steel (MS) rod (6 mm thickness and $12 \mathrm{~mm}$ diameter) with ostensible weight constituent (wt. \%) of $0.8 \% \mathrm{Mn}, 0.04 \% \mathrm{P}, 0.05 \% \mathrm{~S}$, $0.16 \% \mathrm{C}$ and $98.95 \%$ Fe was divided with hacksaw into 3 distinctive categories of 7 samples each. The circular surface end of the steel samples was grinded and leveled with emery papers of different grits, and brightened with $6 \mu \mathrm{m}$ diamond fluid. The samples were subsequently washed with deionized $\mathrm{H}_{2} \mathrm{O}$ and $\mathrm{CH}_{3} \mathrm{COCH}_{3}$. Celery (CL) and pomegranate (PO) were individually chopped to tiny dimensions and grinded. The grinded marsh was squeezed to release the concentrate solution. Green tea (GT) was extricated with a rotary evaporator in $3 \mathrm{~L}$ of deionized $\mathrm{H}_{2} \mathrm{O}$. CL, PO and GT were separately formulated in volumetric concentrations of $10 \%$, $15 \%, 30 \%, 45 \%, 60 \%, 75 \%$, and $90 \%$ in $200 \mathrm{~mL}$ of $0.5 \mathrm{M} \mathrm{H}_{2} \mathrm{SO}_{4}$ solution. MS specimens were independently submerged in $200 \mathrm{~mL}$ of $0.5 \mathrm{M} \mathrm{H}_{2} \mathrm{SO}_{4}$ solution with the plant distillates at specific concentration and weighed every $24 \mathrm{~h}$ for a total of $240 \mathrm{~h}$ with Oarhus weighing balance in the physical metallurgy laboratory. Corrosion rate, $C_{R}(\mathrm{~mm} / \mathrm{y})$ was enumerated from Eq. (1) [32];

$C_{R}=\left[\frac{87.6 \omega}{D A t}\right]$

$\omega$ illustrates weight loss ( $\mathrm{mg}), D$ illustrates density $\left(\mathrm{g} / \mathrm{cm}^{3}\right), A$ illustrates total exposed surface area of MS specimen $\left(\mathrm{cm}^{2}\right), 87.6$ is a corrosion rate constant and $t$ illustrates is the time (h). Inhibition efficiency $(\eta)$ was determined from Eq. (2) [33];

$\eta=\left[\frac{\omega_{1}-\omega_{2}}{\omega_{1}}\right]$

$\omega_{1}$ illustrates weight loss of MS from the acid solution without plant distillates while $\omega_{2}$ illustrates weight loss of MS at determined CL, PO and GT concentrations. Dual-factor mono level experimental ANOVA test ( $\mathrm{F}$ - test) was employed to estimate the statistical influence of the plant distillate concentrations and exposure time on their inhibition performance. The evaluation was done at confidence level of 95\% i.e. a significance level of $\alpha=0.05$ with respect to the following equations. The addition of squares along the columns (exposure time) was enumerated from Eq. (3) while the addition of squares along rows (distillate concentration) was enumerated from Eq. (4). The total addition of squares was enumerated from Eq. (5).
$S S_{c}=\frac{\sum T_{c}^{2}}{n r}-\frac{T^{2}}{N}$

Addition of squares along the rows (plant distillate concentration)

$S S_{r}=\frac{\sum T_{r}^{2}}{n c}-\frac{T^{2}}{N}$

Total addition of squares

$S S_{\text {Total }}=\sum x^{2}-\frac{T^{2}}{N}$

\section{Results and discussion}

\subsection{Coupon measurement}

Tables 1-3 presents the corrosion rate outputs of MS at $0 \%-90 \%$ concentration of CL, PO and GT distillates for 216 h. Tables 4-6 shows the corresponding inhibition efficiency values obtained for CL, PO and GT distillates. Observation of Table 1 depict the significant variation between the corrosion rate of MS without CL distillates and the values obtained in the presence of specific $\mathrm{CL}$ distillate concentration. The corrosion rate of MS without CL distillate varied from $137.92 \mathrm{~mm} / \mathrm{y}$ at $24 \mathrm{~h}$ to $50.54 \mathrm{~mm} / \mathrm{y}$ at $216 \mathrm{~h}$. This figure is significantly high and signifies accelerated degradation of MS in the acid solution due to oxidation of MS by $\mathrm{SO}_{4}^{2-}$ anions. The redox reaction mechanism causes $\mathrm{Fe}^{2+}$ ions to pass into the acid solution causing degradation of the steel [34]. The visible reduction in corrosion rate with time is due to the gradual weakening of the electrolyte [35]. At $15 \% \mathrm{Cl}$ distillate concentration the corrosion rate has decreased to values between $53.09 \mathrm{~mm} / \mathrm{y}$ at $24 \mathrm{~h}$ to $52.51 \mathrm{~mm} / \mathrm{y}$ at $216 \mathrm{~h}$. The value is relatively high and shows lack of effective inhibitor protection of MS. The trend continued but no effective inhibition protection was observed till $60 \% \mathrm{CL}$ distillate concentration where the corrosion rate at $216 \mathrm{~h}$ has reduced to $21.35 \mathrm{~mm} / \mathrm{y}$. Beyond $60 \% \mathrm{CL}$ distillate concentration, the corrosion rate of MS decreased significantly with final values of $7.11 \mathrm{~mm} / \mathrm{y}$ and $2.14 \mathrm{~mm} / \mathrm{y}$ at $75 \%$ and $90 \% \mathrm{CL}$ distillate concentration signifying effective inhibition performance. The same observation occurred for MS in the presence of PO and GT distillates. MS corrosion rate at $15 \% \mathrm{PO}$ and GT distillate concentration at $24 \mathrm{~h}$ of exposure time are $39.29 \mathrm{~mm} / \mathrm{y}$ and $71.66 \mathrm{~mm} / \mathrm{y}$ whereas at $216 \mathrm{~h}$ of exposure time, corrosion rate values of $47.49 \mathrm{~mm} / \mathrm{y}$ and $51.77 \mathrm{~mm} / \mathrm{y}$ were observed. At 75\% PO and GT distillate concentration, MS corrosion rate values are $8.27 \mathrm{~mm} / \mathrm{y}$ and $17.08 \mathrm{~mm} / \mathrm{y}$ at

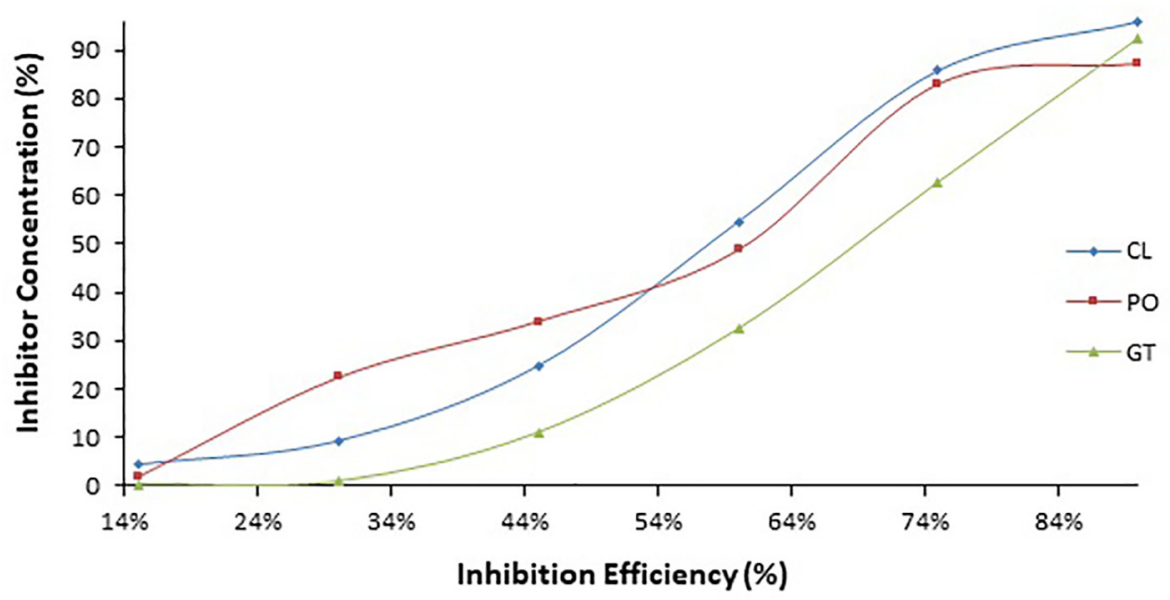

Fig 1. Comparative plot of plant distillate inhibition efficiency versus distillate concentration at $216 \mathrm{~h}$. 
Table 1

Corrosion rate result $(\mathrm{mm} / \mathrm{y})$ of MS at specific concentrations of $\mathrm{CL}(\mathrm{n}=1)$.

\begin{tabular}{|c|c|c|c|c|c|c|c|}
\hline \multirow[b]{2}{*}{ Exp. Time (h) } & \multicolumn{7}{|c|}{ CL Conc. (\%) } \\
\hline & $0 \% \mathrm{CL}$ & $15 \% \mathrm{CL}$ & $30 \% \mathrm{CL}$ & $45 \% \mathrm{CL}$ & $60 \% \mathrm{CL}$ & $75 \% \mathrm{CL}$ & $90 \% \mathrm{CL}$ \\
\hline 24 & 137.92 & 53.09 & 50.19 & 15.47 & 5.22 & 1.24 & 1.49 \\
\hline 48 & 137.92 & 53.09 & 50.19 & 15.47 & 5.22 & 1.24 & 1.49 \\
\hline 72 & 108.56 & 59.84 & 48.82 & 16.22 & 6.63 & 1.65 & 0.90 \\
\hline 96 & 84.46 & 65.81 & 57.41 & 26.58 & 11.93 & 3.38 & 1.24 \\
\hline 120 & 69.93 & 63.00 & 54.38 & 27.47 & 12.08 & 3.59 & 1.54 \\
\hline 144 & 75.82 & 64.99 & 59.19 & 33.46 & 17.02 & 5.40 & 1.91 \\
\hline 168 & 64.98 & 63.14 & 57.86 & 35.04 & 18.15 & 5.66 & 1.88 \\
\hline 192 & 56.86 & 57.16 & 53.35 & 36.59 & 19.95 & 6.47 & 2.03 \\
\hline 216 & 50.54 & 52.51 & 49.84 & 37.80 & 21.35 & 7.11 & 2.14 \\
\hline
\end{tabular}

Table 2

Corrosion rate result $(\mathrm{mm} / \mathrm{y})$ of MS at specific concentrations of $\mathrm{PO}(\mathrm{n}=1)$.

\begin{tabular}{|c|c|c|c|c|c|c|c|}
\hline \multirow[b]{2}{*}{ Exp. Time (h) } & \multicolumn{7}{|c|}{ PO Conc. (\%) } \\
\hline & $0 \%$ PO & $15 \% \mathrm{PO}$ & $30 \%$ PO & $45 \% \mathrm{PO}$ & $60 \% \mathrm{PO}$ & $75 \% \mathrm{PO}$ & $90 \% \mathrm{PO}$ \\
\hline 24 & 113.22 & 39.29 & 27.44 & 20.35 & 11.5 & 4.94 & 1.02 \\
\hline 48 & 113.22 & 39.29 & 27.44 & 21.8 & 11.5 & 4.94 & 2.51 \\
\hline 72 & 82.9 & 44.63 & 31.80 & 24.7 & 12.87 & 4.76 & 2.30 \\
\hline 96 & 68.97 & 50.54 & 39.85 & 31.1 & 18.11 & 7.54 & 2.56 \\
\hline 120 & 65.05 & 48.33 & 37.96 & 30.77 & 18.93 & 7.43 & 2.73 \\
\hline 144 & 63.46 & 50.69 & 40.28 & 32.64 & 21.01 & 8.04 & 5.53 \\
\hline 168 & 65.02 & 50.70 & 39.39 & 31.99 & 22.04 & 7.95 & 5.78 \\
\hline 192 & 56.89 & 48.90 & 38.29 & 28.58 & 23.05 & 8.13 & 6.59 \\
\hline 216 & 50.57 & 47.49 & 37.44 & 31.84 & 23.84 & 8.27 & 6.2 \\
\hline
\end{tabular}

Table 3

Corrosion rate result $(\mathrm{mm} / \mathrm{y})$ of MS at specific concentrations of GT $(\mathrm{n}=1)$.

\begin{tabular}{|c|c|c|c|c|c|c|c|}
\hline \multirow[b]{2}{*}{ Exp. Time (h) } & \multicolumn{7}{|c|}{ GT Conc. (\%) } \\
\hline & $0 \%$ GT & $15 \%$ GT & $30 \%$ GT & $45 \%$ GT & $60 \%$ GT & $75 \%$ GT & $90 \%$ GT \\
\hline 24 & 138.47 & 71.66 & 57.42 & 24.54 & 3.18 & 8.58 & 1.3 \\
\hline 48 & 138.47 & 71.66 & 47.28 & 24.54 & 16.64 & 8.58 & 1.3 \\
\hline 72 & 116.08 & 75.52 & 51.96 & 31.21 & 21.15 & 10.11 & 2.11 \\
\hline 96 & 116.79 & 81.36 & 58.93 & 38.34 & 26.08 & 13.36 & 3.07 \\
\hline 120 & 93.43 & 76.59 & 55.94 & 38.26 & 25.9 & 12.82 & 2.97 \\
\hline 144 & 77.86 & 75.44 & 56.58 & 40.77 & 28.33 & 14.09 & 3.36 \\
\hline 168 & 66.74 & 66.56 & 54.61 & 40.61 & 28.13 & 14.51 & 3.58 \\
\hline 192 & 58.40 & 58.24 & 52.83 & 42.33 & 30.54 & 15.96 & 3.69 \\
\hline 216 & 51.91 & 51.77 & 51.45 & 43.68 & 32.42 & 17.08 & 3.78 \\
\hline
\end{tabular}

Table 4

Inhibition efficiency result (\%) of CL at specific concentrations ( $\mathrm{n}=1)$.

\begin{tabular}{|c|c|c|c|c|c|c|}
\hline \multirow[b]{2}{*}{ Exp. Time (h) } & \multicolumn{6}{|c|}{ CL Conc. (\%) } \\
\hline & $15 \% \mathrm{CL}$ & $30 \% \mathrm{CL}$ & $45 \% \mathrm{CL}$ & $60 \% \mathrm{CL}$ & $75 \% \mathrm{CL}$ & $90 \% \mathrm{CL}$ \\
\hline 24 & 70.15 & 71.79 & 91.3 & 97.07 & 99.3 & 99.16 \\
\hline 48 & 66.38 & 68.22 & 90.2 & 96.7 & 99.21 & 99.06 \\
\hline 72 & 50.9 & 59.94 & 86.69 & 94.56 & 98.65 & 99.26 \\
\hline 96 & 30.32 & 39.21 & 71.85 & 87.37 & 96.42 & 98.69 \\
\hline 120 & 19.14 & 30.21 & 64.75 & 84.5 & 95.39 & 98.02 \\
\hline 144 & 21.2 & 28.23 & 59.43 & 79.36 & 93.45 & 97.69 \\
\hline 168 & 10.68 & 18.15 & 50.43 & 74.33 & 92 & 97.35 \\
\hline 192 & 7.59 & 13.75 & 40.84 & 67.75 & 89.54 & 96.73 \\
\hline 216 & 4.49 & 9.35 & 31.25 & 61.17 & 87.08 & 96.1 \\
\hline 240 & 4.49 & 9.35 & 24.87 & 54.55 & 85.74 & 95.83 \\
\hline
\end{tabular}

$216 \mathrm{~h}$ while at $90 \%$ concentration the corrosion rate values are $6.2 \mathrm{~mm} / \mathrm{y}$ and $3.78 \mathrm{~mm} / \mathrm{y}$ at $216 \mathrm{~h}$. Observation of the inhibition efficiency values indicated in Tables 4-6 gives more detail to the performance of the plant distillates. CL, PO and GT distillates performed poorly from $15 \%$ to $60 \%$ distillate concentration. At $60 \%$ distillate concentration, inhibition efficiency values of $54.55 \%, 48.65 \%$ and $32.39 \%$ were obtained for CL, PO and GT distillates at $216 \mathrm{~h}$ which shows poor inhibition performance. However, at $75 \%$ and
90\% distillate concentration, the inhibition performance of the distillates significantly improved as shown in the Tables. Final values of $85.74 \%, 82.85 \%$ and $62.70 \%$ were obtained at $75 \%$ distillate concentration at $216 \mathrm{~h}$. At $90 \%$ distillate concentration and $216 \mathrm{~h}$ of exposure time, final values of $95.83 \%, 87.08 \%$ and $92.37 \%$ were obtained for CL, PO and GT distillates. Distillates of plant materials contain many active components. The distillates consist of phytochemical compounds and heteroatoms atoms such as $\mathrm{S}, \mathrm{N}, \mathrm{O}, \mathrm{P}$ 
Table 5

Inhibition efficiency result (\%) of PO at specific concentrations $(\mathrm{n}=1)$.

\begin{tabular}{|c|c|c|c|c|c|c|}
\hline \multirow[b]{2}{*}{ Exp. Time (h) } & \multicolumn{6}{|c|}{ PO Conc. (\%) } \\
\hline & $15 \% \mathrm{PO}$ & $30 \% \mathrm{PO}$ & $45 \% \mathrm{PO}$ & $60 \% \mathrm{PO}$ & $75 \% \mathrm{PO}$ & $90 \% \mathrm{PO}$ \\
\hline 24 & 65.29 & 75.76 & 82.03 & 89.84 & 95.64 & 99.10 \\
\hline 48 & 65.29 & 75.76 & 80.74 & 89.84 & 95.64 & 97.78 \\
\hline 72 & 46.16 & 61.64 & 70.20 & 84.47 & 94.26 & 97.22 \\
\hline 96 & 26.72 & 42.22 & 54.90 & 73.74 & 89.06 & 96.29 \\
\hline 120 & 25.69 & 41.64 & 52.69 & 70.90 & 88.58 & 95.81 \\
\hline 144 & 20.13 & 36.53 & 48.58 & 66.90 & 87.34 & 91.28 \\
\hline 168 & 22.02 & 39.42 & 50.80 & 66.10 & 87.78 & 91.12 \\
\hline 192 & 14.05 & 32.69 & 49.77 & 59.48 & 85.71 & 88.42 \\
\hline 216 & 6.09 & 25.96 & 37.04 & 52.85 & 83.64 & 87.75 \\
\hline 240 & 1.89 & 22.37 & 33.96 & 48.65 & 82.85 & 87.08 \\
\hline
\end{tabular}

Table 6

Inhibition efficiency result (\%) of GT at specific concentrations ( $n=1)$.

\begin{tabular}{|c|c|c|c|c|c|c|}
\hline \multirow[b]{2}{*}{ Exp. Time (h) } & \multicolumn{6}{|c|}{ GT Conc. (\%) } \\
\hline & $15 \%$ GT & $30 \%$ GT & $45 \%$ GT & $60 \%$ GT & $75 \%$ GT & $90 \%$ GT \\
\hline 24 & 48.25 & 58.53 & 82.28 & 97.70 & 93.81 & 99.06 \\
\hline 48 & 48.25 & 65.86 & 82.28 & 87.98 & 93.81 & 99.06 \\
\hline 72 & 34.95 & 55.24 & 73.11 & 81.78 & 91.29 & 98.19 \\
\hline 96 & 30.34 & 49.54 & 67.17 & 77.67 & 88.56 & 97.37 \\
\hline 120 & 18.03 & 40.13 & 59.05 & 72.27 & 86.28 & 96.82 \\
\hline 144 & 3.11 & 27.33 & 47.63 & 63.62 & 81.90 & 95.68 \\
\hline 168 & 0.26 & 18.17 & 39.16 & 57.85 & 78.26 & 94.64 \\
\hline 192 & 0.26 & 9.53 & 27.50 & 47.69 & 72.67 & 93.68 \\
\hline 216 & 0.26 & 0.89 & 15.85 & 37.54 & 67.09 & 92.72 \\
\hline 240 & 0.26 & 0.89 & 10.97 & 32.39 & 62.70 & 92.37 \\
\hline
\end{tabular}

etc. which are capable of reacting with the steel surface through physiochemical mechanism and stifling the reduction-oxidation reactions causing corrosion. This reaction processes are strongly dependent on the distillates concentration; hence the increase in inhibition efficiency analogous to distillate concentration $[4,36]$. Comparative plots of the inhibition efficiency CL, PO and GT plant distillates with respect to concentration at $216 \mathrm{~h}$ show a progressive appreciation in inhibition efficiency values. The plot shows the performance of the plant distillates is strongly concentration dependent i.e. accumulation of inhibitor species on the steel exterior to counteract the corrosive effect of the acid species dominates the corrosion inhibition process of the distillates [37].

\subsection{Statistical evaluation}

Results from statistical analysis depicting the mean, standard deviation and margin of error for the inhibition efficiency of $\mathrm{CL}$, PO and GT distillates are shown in Table 7. The standard deviation values show the extent of disparity between the inhibition effi- ciency results for the distillates. Observation of Table 7 shows the standard deviation values decreases with increase in inhibitor concentration. At $90 \%$ inhibitor concentration, the lowest standard deviation values for CL, PO and GT distillates (i.e. 1.27, 4.55 and 2.52 ) were obtained. This indicates that the obtained values at this concentration are closer to the mean value for the results due to the stability of the protonated inhibitor species on the steel exterior. The high standard deviation for the data at lower concentration of the distillates shows that the values vary over a wider range as a result of the instability of the protective covering by the distillates over the steel surface. CL distillate exhibited the lowest standard deviation value at $90 \%$ CL concentration, and the highest standard deviation value at $15 \% \mathrm{CL}$ concentration. The value obtained for margin of error at 95\% confidence level shows that $55 \%, 50 \%$ and $43 \%$ of the inhibition efficiency data of CL, PO and GT plant distillates are above $70 \%+6.4 \%$.

Statistical analysis (ANOVA) was done to evaluate the influence of exposure time and distillate concentration (independent variables) on the inhibition performance of the distillates [38]. The

Table 7

Statistical data for standard deviation and margin of error for the distillate inhibition performance.

\begin{tabular}{|c|c|c|c|c|c|c|}
\hline \multicolumn{7}{|l|}{ CL Distillates } \\
\hline Distillate Conc. & $15 \%$ & $30 \%$ & $45 \%$ & $60 \%$ & $75 \%$ & $90 \%$ \\
\hline SD & 25.22 & 24.08 & 24.21 & 15.06 & 4.99 & 1.27 \\
\hline Mean & 28.53 & 34.82 & 61.16 & 79.74 & 93.68 & 97.79 \\
\hline Margin of Error & $6.4 \%$ & & & & & \\
\hline \multicolumn{7}{|l|}{ PO Distillates } \\
\hline Distillate Conc. & $15 \%$ & $30 \%$ & $45 \%$ & $60 \%$ & $75 \%$ & $90 \%$ \\
\hline SD & 22.49 & 19.19 & 16.56 & 14.51 & 4.69 & 4.55 \\
\hline Mean & 29.33 & 45.40 & 56.07 & 70.28 & 89.05 & 93.19 \\
\hline Margin of Error & $6.5 \%$ & & & & & \\
\hline \multicolumn{7}{|l|}{ GT Distillates } \\
\hline Distillate Conc. & $15 \%$ & $30 \%$ & $45 \%$ & $60 \%$ & $75 \%$ & $90 \%$ \\
\hline SD & 20.41 & 24.53 & 26.48 & 21.75 & 11.16 & 2.52 \\
\hline Mean & 18.40 & 32.61 & 50.50 & 65.65 & 81.64 & 95.96 \\
\hline Margin of Error & $6.4 \%$ & & & & & \\
\hline
\end{tabular}


Table 8

Statistical analysis (ANOVA) for CL, PO and GT plant distillates inhibition performance on MS at 95\% confidence level.

\begin{tabular}{|c|c|c|c|c|c|c|}
\hline \multicolumn{7}{|l|}{$\mathrm{CL}$} \\
\hline Source of Variation & Addition of Squares & Degree of Freedom & Mean Square & Mean Square Ratio (F) & Theoretical Significance Factor & Statistical Relevance (\%) \\
\hline CL Conc. & 278534.96 & 5 & 55706.99 & 457.39 & 2.44 & 93.77 \\
\hline Exp. Time & 13011.95 & 9 & 1445.77 & 11.87 & 2.10 & 4.38 \\
\hline Residual & 5480.73 & 45 & 121.79 & & & \\
\hline Total & 297027.64 & 59 & & & & \\
\hline \multicolumn{7}{|l|}{ PO } \\
\hline Source of Variation & Addition of Squares & Degree of Freedom & Mean Square & Mean Square Ratio (F) & Theoretical Significance Factor & Statistical Relevance (\%) \\
\hline PO Conc. & 251688.15 & 5 & 50337.63 & 830.25 & 2.44 & 95.23 \\
\hline Exp. Time & 9891.13 & 9 & 1099.01 & 18.13 & 2.10 & 3.74 \\
\hline Residual & 2728.33 & 45 & 60.63 & & & \\
\hline Total & 264307.61 & 59 & & & & \\
\hline \multicolumn{7}{|l|}{ GT } \\
\hline Source of Variation & Sum of Squares & Degree of Freedom & Mean Square & Mean Square Ratio (F) & Theoretical Significance Factor & Statistical Relevance (\%) \\
\hline GT Conc. & 221537.87 & 5 & 44307.57 & 461.94 & 2.44 & 91.38 \\
\hline Exp. Time & 16594.41 & 9 & 1843.82 & 19.22 & 2.10 & 6.84 \\
\hline Residual & 4316.27 & 45 & 95.92 & & & \\
\hline Total & 242448.55 & 59 & & & & \\
\hline
\end{tabular}

influence is given in the form of statistical relevance shown in Table 8. It was done to assess the statistical relevance of exposure time and CGT concentration (sources of variation) on the inhibition efficiency values of CGT compound. The results in Table 8 shows that distillate concentration overwhelmingly influence the resulting inhibition efficiency values at statistical relevance factor of 93.77\%, 95.23\% and 91.38\%. The corresponding values for exposure time were relatively and significantly low. However, they are still statistically relevant because the corresponding value for mean square ration is higher than the theoretical significance factor. The theoretical significance factor is the threshold minimum for which a value is statistically relevant. The statistical relevance values obtained showed that the performance of the plant distillates is strongly dependent on its concentration and to a lesser degree acts with respect to variation.

\section{Conclusion}

Gravimetric analysis of the corrosion protection efficiency of celery, pomegranate and green tea distillates on mild steel corrosion in $0.5 \mathrm{M} \mathrm{H}_{2} \mathrm{SO}_{4}$ solution showed the distillates underperformed at low concentrations. Effective inhibition performance was observed at relatively higher distillate concentration with values generally above $90 \%$ at optimal distillate concentration. Statistical analysis through ANOVA shows distillate concentration strongly influence the corrosion inhibition performance of the distillates with values above $90 \%$ compared to exposure time with values below $7 \%$, which is relatively negligible but statistically relevant. Statistical data of the mean, standard deviation and margin of error for the inhibition efficiency of the distillates show the extent of disparity between the values due to the stability of the protonated inhibitor molecules on the steel surface. Analysis of variance evaluated showed distillate concentration strongly influenced the inhibition performance of the extracts.

\section{Declaration of Competing Interest}

The authors declare that they have no known competing financial interests or personal relationships that could have appeared to influence the work reported in this paper.

\section{Acknowledgement}

The author is grateful to Covenant University Ota, Ogun State, Nigeria for their support for this project.

\section{References}

[1] W. Mai, S. Soghrati, R.G. Buchheit, A phase field model for simulating the pitting corrosion, Corros. Sci. 110 (2016) 157-166.

[2] N. Kıcır, G. Tansuğ, M. Erbil, T. Tüken, Investigation of ammonium (2, 4dimethylphenyl)-dithiocarbamate as a new, effective corrosion inhibitor for mild steel, Corros. Sci. 105 (2016) 88-99.

[3] P. Singh, V. Srivastava, M. Quraishi, Novel quinoline derivatives as green corrosion inhibitors for mild steel in acidic medium: electrochemical, SEM, AFM, and XPS studies, J. Mol. Liq. 216 (2016) 164-173.

[4] R.T. Loto, P. Babalola, J. Sánchez, Corrosion polarization behavior and microstructural analysis of AA1070 aluminium silicon carbide matrix composites in acid chloride concentrations, Cogent. Eng. 4 (1) (2017) 1422229, https://doi.org/10.1080/23311916.2017.1422229.

[5] C. Verma, E.E. Ebenso, I. Bahadur, M.A. Quraishi, An overview on plant extracts as environmental sustainable and green corrosion inhibitors for metals and alloys in aggressive corrosive media, J. Mol. Liq. 266 (2018) 577-590, https:// doi.org/10.1016/j.molliq.2018.06.110.

[6] R.E. Melchers, R. Jeffery, Early corrosion of mild steel in seawater, Corros. Sci. 47 (2005) 1678-1693, https://doi.org/10.1016/j.corsci.2004.08.006.

[7] M. Chigondo, F. Chigondo, Recent natural corrosion inhibitors for mild steel: an overview, J. Chem. 2016 (2016) 1-7, https://doi.org/10.1155/2016/6208937.

[8] C. Makrides, N. Hakerman, Inhibition of acid dissolution of metals. I. Some general observations J. Phys. Chem. 59(8) (1955) 707-710. https://doi.org/ $10.1021 / \mathrm{j} 150530 \mathrm{a} 007$.

[9] S.T. Arab, A.M. Al-Turkustani, Corrosion inhibition of steel in phosphoric acid by phenacyldimethyl sulfonium bromide and some of its p-substituted derivatives Port, Electrochim. Acta 24 (1) (2006) 53-69.

[10] N.O. Eddy, E.E. Ebenso, Corrosion inhibition and adsorption properties of ethanol extract of Gongronema latifolium on mild steel in $\mathrm{H}_{2} \mathrm{SO}_{4}$, Pigm. Resin Technol. 39 (2) (2010) 77-83, https://doi.org/10.1108/03699421011028653.

[11] J.I. Bregman, Corrosion Inhibitors, The MacMillan Company, New York, 1963.

[12] M. Mthar, H. Ali, M.A. Quraishi, Corrosion inhibition of carbon steel in hydrochloric acid by organic compounds containing heteroatoms, $\mathrm{Br}$. Corrosion J. 37 (2) (2012) 155-158, https://doi.org/10.1179/ 000705902225002376.

[13] S. Tamil Selvi, V. Raman, N. Rajendran, Corrosion inhibition of mild steel by benzotriazole derivatives in acidic medium, J. Appl. Electrochem. 33 (12) (2003) 1175-1182, https://doi.org/10.1023/B:JACH.0000003852.38068.3f.

[14] F. Bentiss, M. Traisnel, H. Vezin, H.F. Hildebrand, M. Lagrenee, 2,5-Bis(4dimethylaminophenyl)-1,3,4-oxadiazole and 2,5-bis(4dimethylaminophenyl)-1,3,4-thiadiazole as corrosion inhibitors for mild steel in acidic media, Corros. Sci. 46 (11) (2004) 2781-2792, https://doi.org/ 10.1016/j.corsci.2004.04.001.

[15] E.A. Noor, The inhibition of mild steel corrosion in phosphoric acid solutions by some N-heterocyclic compounds in the salt form, Corros. Sci. 47 (1) (2005) 3355, https://doi.org/10.1016/j.corsci.2004.05.026.

[16] Y.G. Bereket, A.B. Balaban, E. Erk, Effect of schiff bases containing pyridyl group as corrosion inhibitors for low carbon steel in $0.1 \mathrm{M} \mathrm{HCl}$. J. Appl. Electrochem. 35(10) (2005) 1025-1032. https://doi.org/10.1007/s10800-005-7336-3.

[17] A.G. Christy, A. Lowe, V. Otieno-Alego, M. Stoll, R.D. Webster, Voltammetric and raman microspectroscopic studies on artificial copper pits grown in simulated potable water, J. Appl. Electrochem. 34 (2) (2004) 225-233, https:// doi.org/10.1023/B:JACH.0000009923.35223.f8.

[18] H. Otmacic, J. Telegdi, K. Papp, E. Stupnisek-Lisac, Protective properties of an inhibitor layer formed on copper in neutral chloride solution, J. Appl. Electrochem. 34 (5) (2004) 545-550, https://doi.org/10.1023/B: JACH.0000021873.30314.eb. 
[19] H. Ma, S. Chen, L. Niu, S. Zhao, S. Li, D. Li, Inhibition of copper corrosion by several Schiff bases in aerated halide solutions, J. Appl. Electrochem. 32 (1) (2002) 65072, https://doi.org/10.1023/A:1014242112512.

[20] M. Elayyachy, B. Hammouti, A. El Idrissi, New telechelic compounds as corrosion inhibitors for steel in $1 \mathrm{M} \mathrm{HCl}$ Appl, Surf. Sci. 249 (2005) 176-182, https://doi.org/10.1016/j.apsusc.2004.11.075.

[21] M. Bouklah, B. Hammouti, M. Lagrenée, F. Bentiss, Thermodynamic properties of 2, 5-bis(4-methoxyphenyl)-1,3,4-oxadiazole as a corrosion inhibitor for mild steel in normal sulfuric acid medium, Corros. Sci. 48 (9) (2006) 28312842, https://doi.org/10.1016/j.corsci.2005.08.019.

[22] M. Ajmal, A.S. Mideen, M.A. Quraishi, 2-hydrazino-6-methyl-benzothiazole as an effective inhibitor for the corrosion of mild steel in acidic solutions, Corros. Sci. 36 (1) (1994) 79-84, https://doi.org/10.1016/0010-938X(94)90110-4.

[23] S.A. Umoren, U.M. Eduok, Application of carbohydrate polymers as corrosion inhibitors for metal substrates in different media: a review, Carbohydr. Polym. 140 (2016) 314-341, https://doi.org/10.1016/j.carbpol.2015.12.038.

[24] K.e. Hu, J. Zhuang, C. Zheng, Z. Ma, L.i. Yan, H. Gu, X. Zeng, J. Ding, Effect of novel cytosine-l-alanine derivative based corrosion inhibitor on steel surface in acidic solution, J. Mol. Liq. 222 (2016) 109-117, https://doi.org/10.1016/ j.molliq.2016.07.008.

[25] B. Ramezanzadeh, H. Vakili, R. Amini, The effects of addition of poly (vinyl) alcohol (PVA) as a green corrosion inhibitor to the phosphate conversion coating on the anticorrosion and adhesion properties of the epoxy coating on the steel substrate, Appl. Surf. Sci. 327 (2015) 174-181, https://doi.org/ 10.1016/j.apsusc.2014.11.167.

[26] R. Mohammadinejad, S. Karimi, S. Iravani, RS. Varma, Plant-derived nanostructures: types and applications, Green Chem. 18 (1) (2016) 20-52, https://doi.org/10.1039/C5GC01403D.

[27] R.S. Varma, Journey on greener pathways: from the use of alternate energy inputs and benign reaction media to sustainable applications of nano-catalysts in synthesis and environmental remediation, Green Chem. 16 (2014) 20272041, https://doi.org/10.1039/C3GC42640H
[28] H. Jeon, C. Lim, J.M. Lee, S. Kim, Chemical assay-guided natural product isolation via solid-supported chemodosimetric fluorescent probe, Chem. Sci. 6 (5) (2015) 2806-2811, https://doi.org/10.1039/C5SC00360A.

[29] C.A. Loto, O.O. Joseph, R.T. Loto, A.P.I. Popoola, Corrosion inhibitive behaviour of camellia sinensis on aluminium alloy in H2SO4, Int. J. Elect. Sci. 9 (3) (2014) 1221-1231.

[30] R.T. Loto, R. Leramo, B. Oyebade, Synergistic combination effect of salvia officinalis and lavandula officinalis on the corrosion inhibition of low-carbon steel in the presence of $\mathrm{SO}_{4}{ }^{2-}$ - and $\mathrm{Cl}^{-}$-containing aqueous environment, J. Fail. Anal. Prev. 18 (6) (2018) 1429-1438.

[31] R.T. Loto, C.A. Loto, Effect of P-phenylediamine on the corrosion of austenitic stainless steel type 304 in hydrochloric acid, Int. J. Elect. Sci. 7 (10) (2012) 9423-9440.

[32] N.C. Ngobiria, O. Akarantaa, N.C. Oforka, E.E. Oguzieb, S.U. Ogbuliec, Inhibition of pseudo-anaerobic corrosion of oil pipeline steel in pipeline water using biomas-derived molecules, Advances Mats. Corros. 2 (2013) 20-25.

[33] C.A. Loto, R.T. Loto, A.P.I. Poopola, Corrosion and plant extracts inhibition of mild steel in HCl, Int. J. Phy. Sci. 6 (15) (2011) 3689-3696.

[34] C. Leygraf, I. O. Wallinder, J. Tidblad, T. Graedel, The morphology of natural rust layers, Atmospheric Corrosion, 2nd Edition, John Wiley \& Sons, Inc., pp. 303315.

[35] Y.B. Amor, L. Bousselmi, H. Takenouti, E. Triki, Influence of sulphate ions on corrosion mechanism of carbon steel in calcareous media. 40(2) (2005) 129136. http://doi.org/10.1179/174327805X29886.

[36] S. Mo, H. Luo, N. Li, Plant extracts as "green" corrosion inhibitors for steel in sulphuric acid, Chem. Pap. 70 (2016) 1131-1143, https://doi.org/10.1515/ chempap-2016-0055.

[37] M.P. Chakravarthy, K.N. Mohana, Adsorption and corrosion inhibition characteristics of some nicotinamide derivatives on mild steel in hydrochloric acid solution, Int. Sch. Res. Notices 2014 (2014) 1-13, https:// doi.org/10.1155/2014/687276.

[38] M. Parveen, M. Mobin, S. Zehra, R. Aslam, L-proline mixed with sodium benzoate as sustainable inhibitor for mild steel corrosion in $1 \mathrm{M} \mathrm{HCl}$ : an experimental and theoretical approach, Sci. Rep. 8 (2018) 7489. 